\title{
REVIEW \\ Evolution of uni- and bifactorial sexual compatibility systems in fungi
}

\begin{abstract}
BPS Nieuwenhuis ${ }^{1,2}$, S Billiard ${ }^{3}$, S Vuilleumier ${ }^{4}$, E Petit $^{5}$, ME Hood $^{6}$ and T Giraud ${ }^{6,7}$
Mating systems, that is, whether organisms give rise to progeny by selfing, inbreeding or outcrossing, strongly affect important ecological and evolutionary processes. Large variations in mating systems exist in fungi, allowing the study of their origin and consequences. In fungi, sexual incompatibility is determined by molecular recognition mechanisms, controlled by a single mating-type locus in most unifactorial fungi. In Basidiomycete fungi, however, which include rusts, smuts and mushrooms, a system has evolved in which incompatibility is controlled by two unlinked loci. This bifactorial system probably evolved from a unifactorial system. Multiple independent transitions back to a unifactorial system occurred. It is still unclear what force drove evolution and maintenance of these contrasting inheritance patterns that determine mating compatibility. Here, we give an overview of the evolutionary factors that might have driven the evolution of bifactoriality from a unifactorial system and the transitions back to unifactoriality. Bifactoriality most likely evolved for selfing avoidance. Subsequently, multiallelism at matingtype loci evolved through negative frequency-dependent selection by increasing the chance to find a compatible mate.

Unifactoriality then evolved back in some species, possibly because either selfing was favoured or for increasing the chance to find a compatible mate in species with few alleles. Owing to the existence of closely related unifactorial and bifactorial species and the increasing knowledge of the genetic systems of the different mechanisms, Basidiomycetes provide an excellent model for studying the different forces that shape breeding systems.
\end{abstract}

Heredity (2013) 111, 445-455; doi:10.1038/hdy.2013.67; published online 10 July 2013

Keywords: Bipolar; tetrapolar; mating system; sexual compatibility; self-incompatibility

\section{INTRODUCTION}

The mating system is one of the most variable traits in the living world, with organisms giving rise to progeny by selfing, inbreeding or outcrossing. Understanding what shapes an organism's mating system is of fundamental importance because patterns of inheritance drastically affect major evolutionary and ecological processes such as adaptation (Charlesworth and Charlesworth, 1995; Otto, 2009), colonization (Richards, 2003; Busch, 2011), accumulation of transposable elements (Boutin et al., 2012), speciation (Gibson et al., 2012), genomic architecture or rates of molecular evolution (Nygren et al., 2011). Evolutionary transitions in reproductive systems generally involve changes that increase the fitness of novel genotypes that spread and replace ancestral ones (Barrett, 2010). Because of the huge diversity in their mating systems, the low number of genes involved and their experimental tractability, fungi constitute an excellent group of model systems for studying evolutionary forces driving mating systems (Czárán and Hoekstra, 2004; Billiard et al., 2011; Billiard et al., 2012; Gioti et al., 2012; Perrin, 2012).

In many fungi, the potential of syngamy is determined at the haploid stage by mating-type gene(s): only haploids carrying different mating-type alleles at the mating-type locus/loci can successfully mate (see Figure 1 for two generalized fungal life cycles). Such fungi are called heterothallic. In fungi, haploid mating types most likely evolved to prevent same-clone mating (Czárán and Hoekstra, 2004; Billiard et al., 2011; Billiard et al., 2012; but see Perrin, 2012). In Ascomycete fungi (yeasts, moulds) and more basally derived fungi (Mucoromycotina; Idnurm et al., 2008), mating type is defined by a single locus (the mating type is unifactorial, aka bipolar), possessing genetic idiomorphs that are distinct in the two mating types, which are not called alleles because of the uncertainty surrounding their homology (Metzenberg and Glass, 1990). The Basidiomycota (including mushrooms, rusts and smuts) have evolved a genetic system with two different mating-type loci: only cells carrying different alleles at both loci can mate to produce viable progeny (the determinism of mating type is bifactorial, aka tetrapolar).

Bifactorial incompatibility systems are not restricted to fungi; instead, they have also been found in different plant species of the Poaceae family (Klaas et al., 2011), in different tristylous plants (Barrett and Shore, 2008), in tunicates (Harada et al., 2008) and in the social amoeba of the genus Physarum (Moriyama and Kawano, 2010). Of these bifactorial systems, only that of the social amoeba is similar to that of the Basidiomycetes in that compatibility occurs only when both loci carry different alleles. In the others, compatibility at either of the loci results in successful mating.

In fungi, bifactoriality most likely evolved once from a primary unifactorial system, as all the most basally derived fungal groups

\footnotetext{
${ }^{1}$ Laboratory of Genetics, Wageningen University, Wageningen, The Netherlands; ${ }^{2}$ Department of Evolutionary Biology, Uppsala University, Uppsala, Sweden; ${ }^{3}$ Laboratoire de Génétique et Evolution des Populations Végétales, UMR CNRS 8198, Université des Sciences et Technologies de Lille - Lille1, F-59655 Villeneuve d'Ascq Cedex, France; ${ }^{4}$ Department of Ecology and Evolution, University of Lausanne, Lausanne, Switzerland; ${ }^{5}$ Department of Biology, Amherst College, Amherst, MA, USA; ${ }^{6}$ Ecologie, Systématique et Evolution, Université Paris-Sud, Orsay, France and ${ }^{7}$ CNRS UMR 8079, F-91405 Orsay Cedex, France

Correspondence: Dr BPS Nieuwenhuis, Department of Evolutionary Biology, Uppsala University, Evolutionary Biology Centre, EBC, Norbyvägen 18D, Uppsala 75236, Sweden. E-mail: bart.nieuwenhuis@ebc.uu.se
}

Received 11 January 2013; revised 7 June 2013; accepted 10 June 2013; published online 10 July 2013 


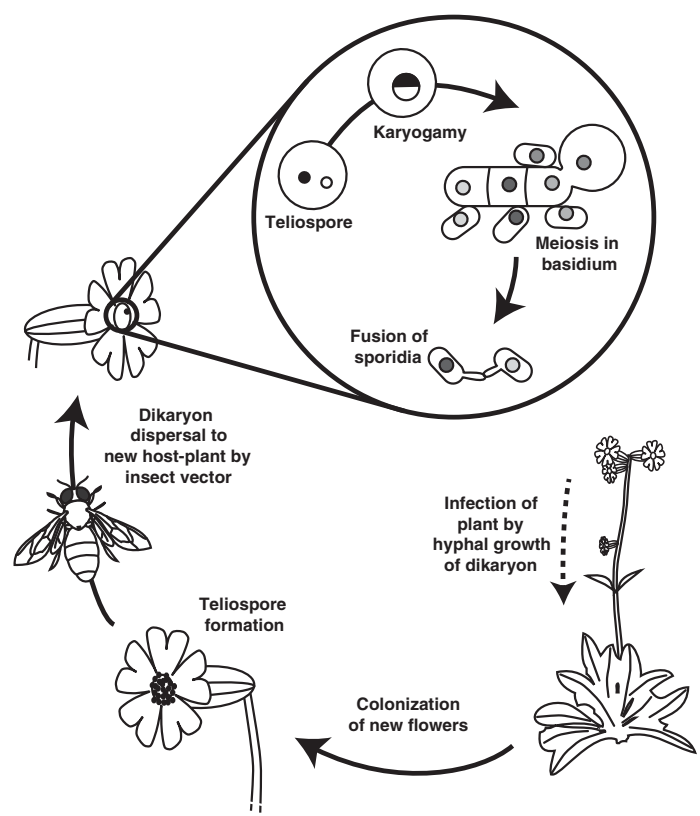

b

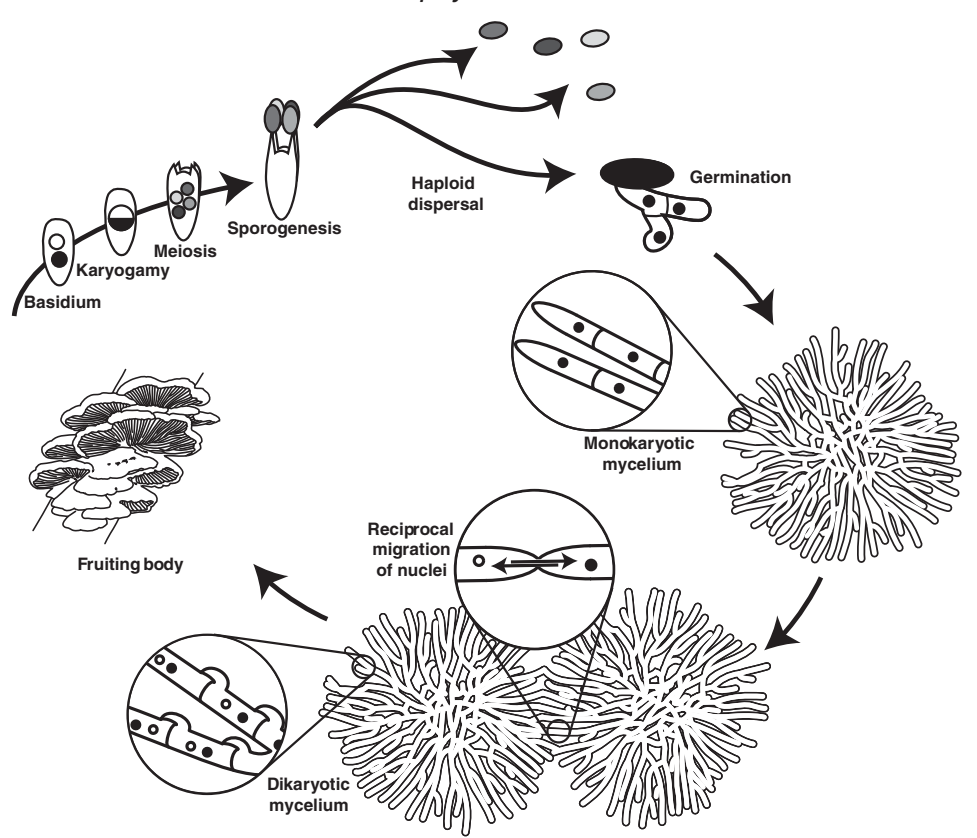

Figure 1 General life cycles of yeast-forming and mushroom-like Basidiomycetes. (a) The Microbotryum violaceum life cycle as an example of a yeast-like Basidiomycete. The yeast-like generalized life cycle starts with a haploid meiotic product called the sporidium that can undergo vegetative haploid growth by mitotic cell duplication. Mating occurs by fusion of two haploid cells, either sporidia or cells of the basidium, but without karyogamy and resulting in a dikaryon. In Microbotryum, the yeast stage is very brief, as most crosses occur between cells within the same tetrad. The dikaryon is a long-lasting stage and assumes a hyphal growth form that infects the host plants. In the infected flowers, the diploid stage is achieved as dispersing teliospores are formed, which upon germination produce the club-shaped basidium where meiosis occurs. (b) The Schizophyllum commune life cycle as an example for the mushroom-forming fungi. A haploid spore germinates and grows by forming a mycelium — the homokaryon-in which a single type of haploid nuclei is present in all hyphae. Mating occurs by fusion of hyphae of different individuals, which exchange nuclei. The nuclei migrate back from the point of plasmogamy and through the entire mycelium, thereby forming a long-lasting dikaryon. When the conditions are suitable, the dikaryon forms a fruiting body, the mushroom, in which basidia are formed. Resulting haploid air-borne spores disperse at long distances and germinate to form a monokaryon.

possess a single locus determining the mating type (Whitehouse, 1949; Raper, 1966; Heitman et al., 2007; Kües et al., 2011). Only Basidiomycetes, forming one of the most recent fungal clades, include bifactorial species. Several hypotheses have been invoked to explain the evolution of bifactoriality. The most popular explanation is that bifactoriality promotes outcrossing (Hsueh et al., 2008; Heitman et al., 2013). Because the two mating-type loci are unlinked, gametes of four different incompatibility types can be formed in a meiotic tetrad, rather than segregating into just two incompatibility types under unifactorial systems (Figure 2). This difference in the number of possible incompatibility phenotypes is the reason why the terms tetrapolarity and bipolarity are often used to describe the breeding system of fungi. Bifactoriality is thus less favourable for diploid selfing compared with unifactoriality, as the chance of being compatible for any two haploid products from the sample diploid parent is 50\% in a unifactorial cross compared with only $25 \%$ in a bifactorial system with completely unlinked mating-type loci (Hsueh et al., 2008).

Some Basidiomycetes have secondarily evolved a unifactorial mating system from the bifactorial system, either because the mating type loci became linked, such as in Ustilago hordei (Bakkeren and Kronstad, 1994), or because one locus is not controlling compatibility for syngamy any more, such as in Coprinellus disseminatus (James et al., 2006). Multiple transitions from bifactorial to unifactorial systems have been documented (Billiard et al., 2011; Kües et al., 2011). A few species appear intermediate between the two systems, with linkage between the two mating-type loci but still rare events of recombination (see the section 'Intermediate systems'; Coelho et al., 2010).
Another important difference between unifactorial and bifactorial systems is the number of alleles at the mating-type locus or loci. All bifactorial species for which this has been investigated possess multiple alleles (that is, more than two) at least for one of their mating-type loci, whereas unifactorial species often are biallelic at the mating-type locus. Under an outcrossing mating system and a numeric limitation of mates (for example, low population densities), a novel or rare allele has increased chances to confer compatibility and should therefore be selected for (Fisher, 1941; May et al., 1999). This is expected to select for an increased number of alleles.

So far, the evolutionary advantages and drawbacks of uni- versus bifactoriality have been explored surprisingly little. The aim of this opinion paper is therefore to discuss the possible evolutionary advantages and drawbacks of bifactoriality versus unifactoriality, to review the data on the evolution of the mating-type system in Basidiomycetes, to propose a scenario for the evolution of the system in Basidiomycetes and to suggest some tests of various hypotheses. We first investigate why bifactoriality might have arisen from a primary unifactorial system. Second, we question why bifactoriality has evolved back multiple times towards secondary unifactoriality.

\section{TRANSITION FROM A PRIMARY UNIFACTORIAL TO A BIFACTORIAL SYSTEM}

As mentioned above, bifactorial incompatibility in fungi has so far only been described in Basidiomycota-except possibly one case (Cayley, 1931; Debuchy et al., 2010). Bifactoriality has therefore most likely evolved in Basidiomycota after their divergence from 
a Unifactorial: one MAT locus

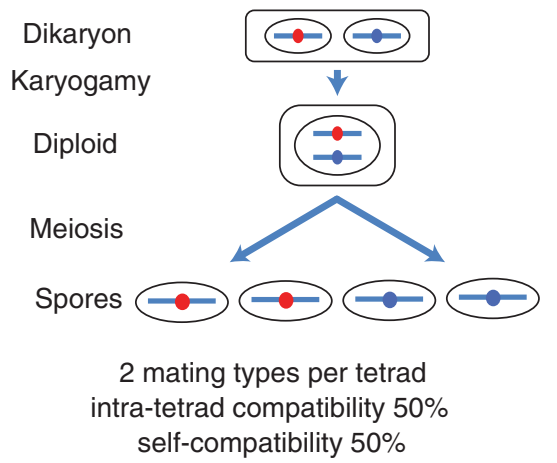

d Bifactorial: two MAT loci

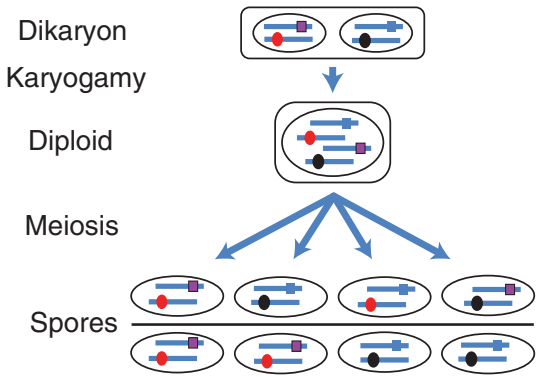

2 mating types or 4 mating types intra-tetrad compatibility $50 \%$ or $25 \%$ self-compatibility $25 \%$ b

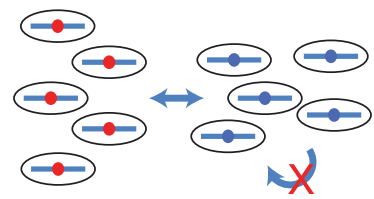

Compatibility with $50 \%$ of the individuals in the population
C Multiallelic

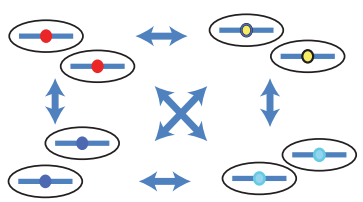

Compatibility with $1-p_{i}$ of the individuals in the population e

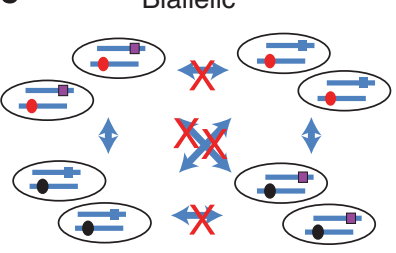

Compatibility with $25 \%$ of the individuals in the population

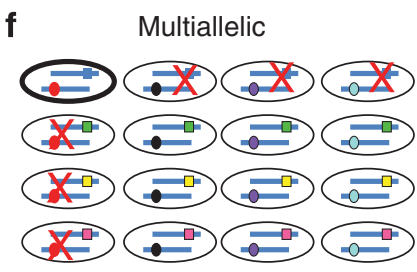

Compatibility with $\left(1-p_{h d}\right)\left(1-p_{p r}\right)$ of the individuals in the population

Figure 2 Overview of fungal compatibility between haploid individuals for unifactorial and bifactorial systems. (a) A unifactorial dikaryon produces gametes of two different mating types, resulting in $50 \%$ intra-tetrad compatibility. Each unifactorial spore is compatible with $50 \%$ of the population in a biallelic system (b) and with 1- $p_{i}$ in a multiallelic population (c). (d) A bifactorial dikaryon will produce gametes of four different types. In each tetrad formed, either two (in $1 / 3$ of tetrads) or four (in $2 / 3$ of tetrads) different mating types are produced (the figure shows only half of the options), resulting in 50 or $25 \%$ intra-tetrad compatibility, respectively. Each spore is on average compatible with $25 \%$ of the spores produced by the same dikaryotic mycelium. (e) In a biallelic species, each haploid individual is compatible with $25 \%$ of the population. (f) When multiple alleles exist, each spore is compatible with ( $\left.1-p_{h d}\right)$ $\left(1-p_{p r}\right)$ of the population. In this example, four alleles exist for each mating-type locus, resulting in compatibility to $\sim 56 \%$ of the population, under equal allele frequencies and random mating.

Ascomycota (see phylogeny in Figure 3 and Whitehouse, 1949; Raper, 1966; Kües et al., 2011). Owing to the occurrence of multiple unifactorial species within the Basidiomycetes, the single origin of bifactoriality is still debated. However, all unifactorial Basidiomycete species for which this has been investigated show genomic signatures that they evolved secondarily from a bifactorial system (see the section 'Reversion to unifactorial mating' and Kües et al., 2011), which would thus be ancestral in the Basidiomycete clade. Similarly, all known fungal species with multiple mating-type alleles belong to Basidiomycetes-again except one case (Cisar and TeBeest, 1999). We therefore consider that the bifactorial mating system arose once and from a biallelic unifactorial system, either by first acquiring multiple alleles followed by acquisition of a second mating-type locus, or by first evolving a bifactorial mating-type system that then became multiallelic in many species. The first scenario is unlikely, as all known multiallelic unifactorial Basidiomycetes appear to be secondary reversions to unifactoriality (reviewed in Kües et al., 2011). We thus favour the hypothesis that bifactoriality evolved after the split with the Ascomycota (Whitehouse, 1949; Raper, 1966; Kües et al., 2011) and that multiallelism evolved afterwards.

\section{Genomic changes}

Incompatibility in Ascomycetes and in the more basal Mucoromycetes is regulated by a single mating-type locus with two genic forms, called idiomorphs as their common ancestry is uncertain (Metzenberg and Glass, 1990). Recently it has been suggested that idiomorphs may be alleles, but with such an ancient trans-specific polymorphism, for instance caused by long-term balanced selection (Devier et al., 2009), that their homology is no longer obvious (Idnurm et al., 2008; Debuchy et al., 2010).

Recognition of a compatible mate occurs by a pheromone/receptor interaction. In Ascomycetes and Mucoromycetes, each mating type produces one type of pheromone, activating the receptor of the other mating type, and they produce a receptor that responds to the pheromone from the other mating type (Kothe, 2008). Even though the genes encoding both types of pheromones and receptor associated with mating types are present in all cells, only one set is expressed in any given haploid as regulated by the idiomorph at the mating-type locus (Figure 4a; Tsong et al., 2003; Idnurm et al., 2008). Thus, the pheromone/receptor system acts to mediate recognition between the two mating types, but the genes of the pheromone/receptor system are not a locus controlling mating compatibility. After fusion, dimerization of proteins (of an HMG type in Mucoromycetes, and of a HMG, homeodomain or alpha-box type in Ascomycetes) encoded by each of the idiomorphs of the actual mating-type locus initiates a developmental switch to a diploid or dikaryotic growth form (Tsong et al., 2003; Debuchy et al., 2010).

Also in Basidiomycetes, cell recognition and fusion are controlled by a pheromone/receptor system; however, in contrast to the Ascomycete system, the Basidiomycete system resides at a single locus (hereafter called the $P R$ locus) and is allelic (Figure 4b), and even multiallelic in many species (Figure 2; Kües et al., 2011). Each mating 

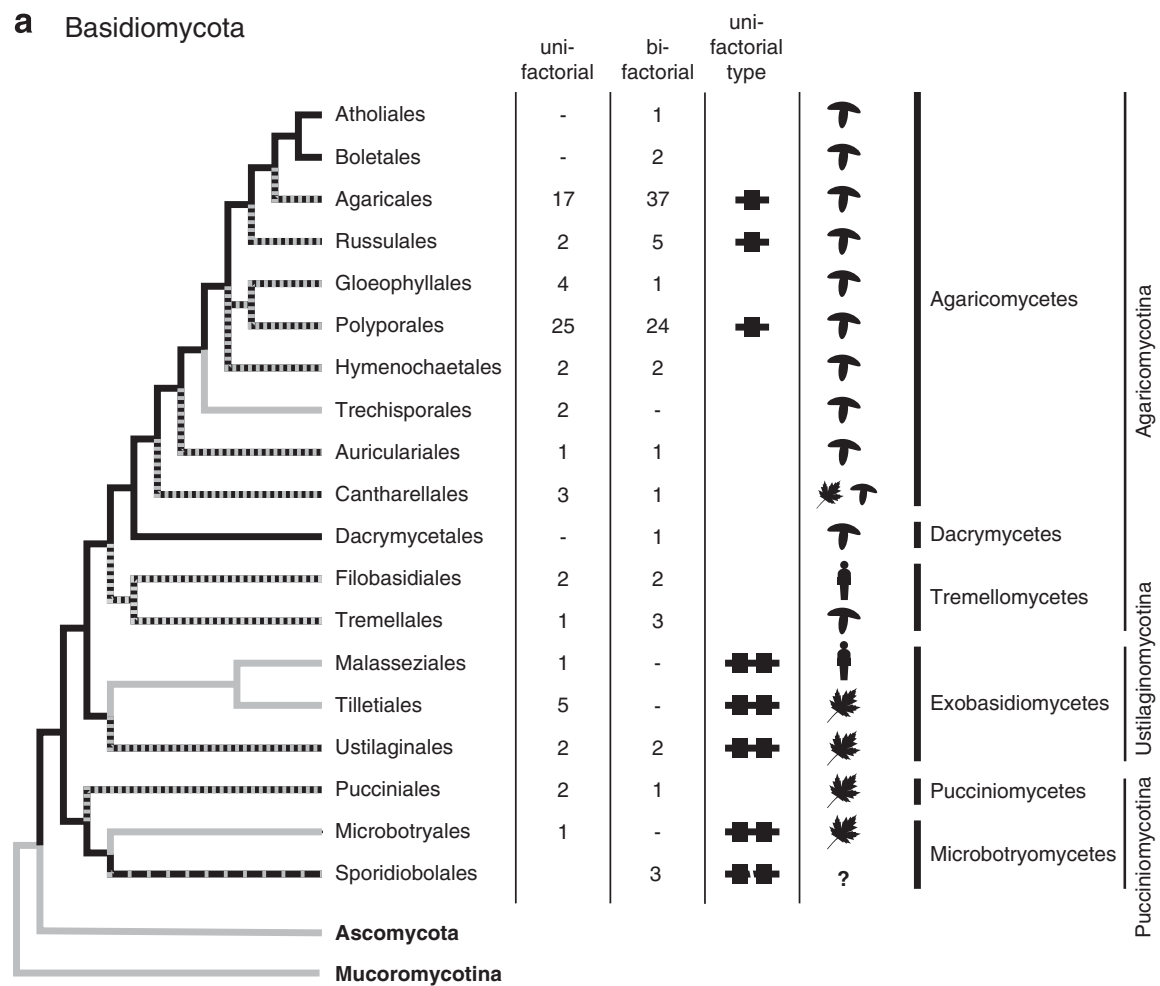

b Agaricales

$\begin{array}{cc}\text { uni- } & \text { bi- } \\ \text { factorial } & \text { factorial }\end{array}$

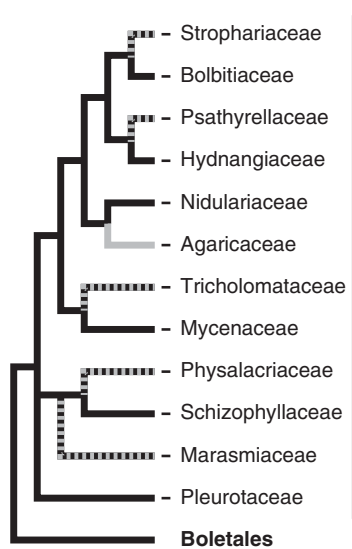

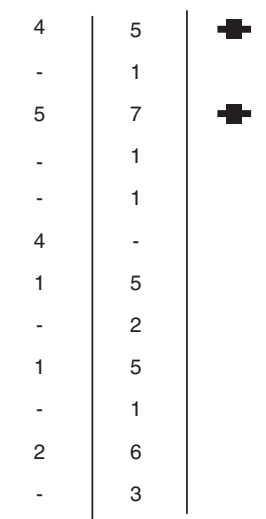

C Polyporales

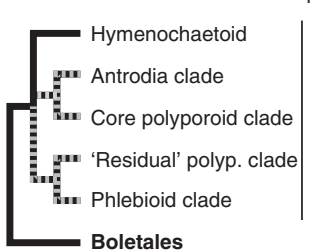

uni- bi-

$\left|\begin{array}{c}- \\ 14 \\ 1 \\ 2 \\ 9\end{array}\right|$
factorial factorial

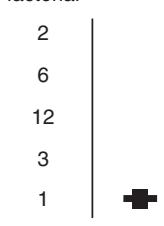

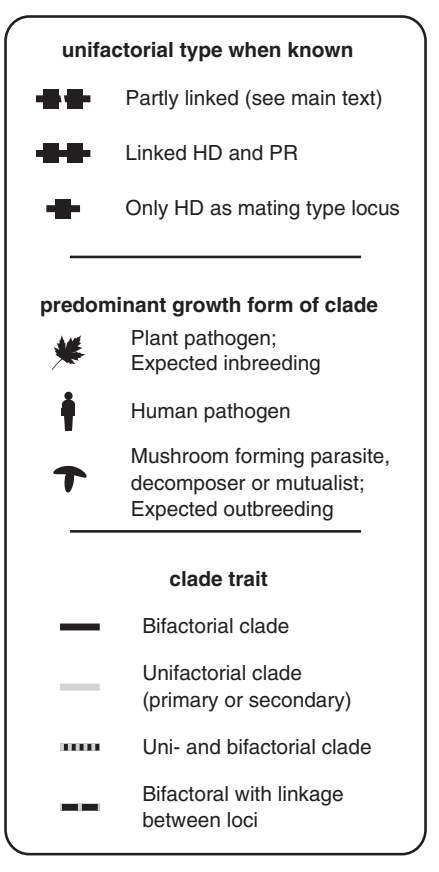

Figure 3 Phylogeny of the Basidiomycota showing the presence of unifactorial and bifactorial mating systems, assuming that bifactoriality arose before the split of the Pucciniomycotina. Note that unifactoriality in the tree refers both to primary and secondary bifactorial systems. Phylogenies are given for (a) higher level clade (based on Hibbett and Donoghue, 2001; Begerow et al., 2006; Hibbett et al., 2007), (b) the Agaricales (Matheny et al., 2006) and (c) the Polyporales (Matheny et al., 2007). For each clade the number of species with unifactorial and bifactorial mating systems is indicated. The type of secondary unifactoriality (when known for a member of the clade) is indicated by a symbol. For each clade also the main ecological type is given. Data on species and their characteristics on which this figure is based, together with references, can be found in Supplementary Table S1.

type carries only receptor and pheromone genes specific for that mating type. In general, syngamy can occur only between individuals carrying different alleles. In the Agaricomycotina (mushroom- forming fungi), syngamy occurs regardless of the alleles at the $P R$ locus, although if the two gametes are incompatible at the $P R$ system mating is quickly aborted (Kües et al., 2011). 


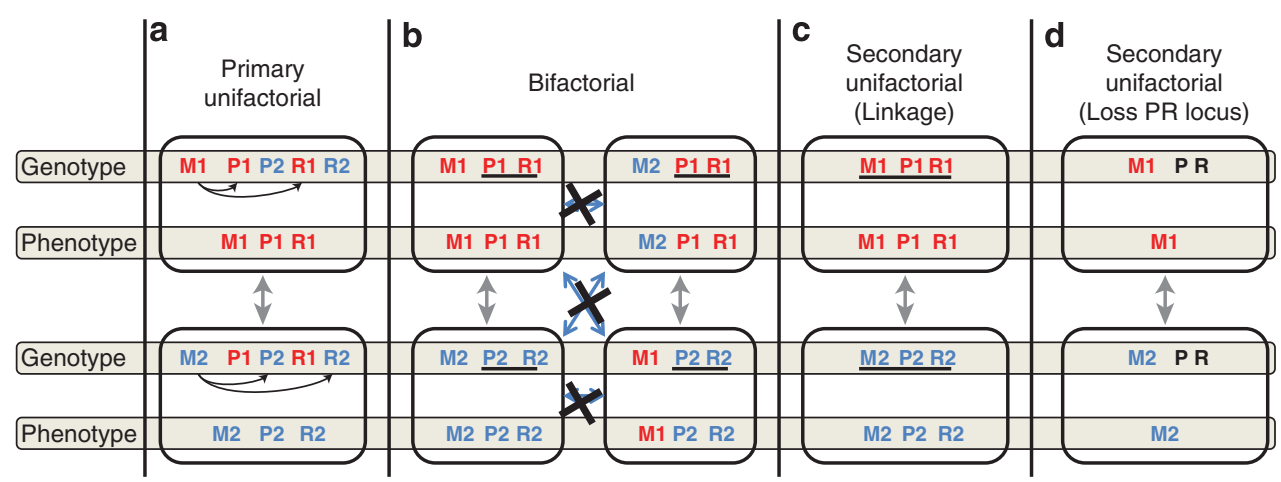

Figure 4 Schematic overview of the haplotypes and phenotypes of primary and secondary unifactorial systems and the bifactorial system in fungi. Underlined loci are linked. $M$ refers to the mating-type locus in primary unifactorial species or the $H D$ locus in Basidiomycetes. $P$ and $R$ refer to pheromone and receptor loci, respectively. 1 and 2 indicate different alleles at each locus. (a) A primary unifactorial system as observed in, for instance, Phycomyces blakesleeanus or Saccharomyces cerevisiae contains both pheromone and receptor types $(P$ and $R$ ), but depending on the allele at the mating type $(M)$ only one type of $P$ and $R$ is expressed. (b) In a bifactorial system the $P$ and $R$ genes are linked together. Only when the $H D$ and $P R$ loci differ are haploid cells compatible. (c) Secondary unifactoriality due to linkage of both the $H D$ and $P R$ system. Each cell is compatible at both systems. (d) Secondary unifactoriality due to loss on the $P R$ system for compatibility. Each cell is compatible with cells that have a different allele at the $H D$ locus. $P R$ is still present but is not polymorphic. For types (a-c), compatibility is possible only when both the $H D$ and the $P R$ system are compatible, except for secondary unifactoriality with loss of $P R$ functionality (d), where compatibility is defined only by the HD locus.

In Basidiomycetes, after syngamy, a mycelium is formed that is viable only if the product of mating is also heterozygous at the second mating-type locus, which encodes homeodomain proteins functioning as transcriptional regulators (the $H D$ locus; Kües et al.). This second locus is among others involved in regulating the growth of the dikaryon (Fraser et al., 2007) and acts as a switch from pre- to postmating development, including from yeast to filamentous growth in smuts and rusts (Feldbrügge et al., 2004). Successful mating (that is, leading to a viable dikaryon) thus occurs only between cells carrying different alleles at both mating-type loci. The key proximal mechanism allowing bifactoriality is therefore the decoupling of the $P R$ and $H D$ loci in Basidiomycetes, which are not regulated by the $H D$ or $H M G$ genes any more but instead independently control successful syngamy and successful dikaryotic growth, respectively.

The Basidiomycete bifactorial mating-type system, with $P R$ and $H D$ loci, shows remarkable similarities with some species of the Saccharomycotina and Taphrinomycotina, two basal groups of the Ascomycota, which have homeodomain genes at one of the mating-type idiomorphs (Idnurm et al., 2008) and one pheromone/receptor system comparable to the Basidiomycete $P R$ system (Coppin et al., 1997; Fowler et al., 1999; Gonçalves-Sá and Murray, 2011). The alternative idiomorph present in these Ascomycotina and basal Mucoromycotina (of the HMG type; Dyer, 2008; Idnurm et al., 2008) was most likely lost early in the Basidiomycete lineage (Dyer, 2008; Kües et al., 2011). In Basidiomycetes, the pheromone and receptor genes became linked (Bölker et al., 1992; Wendland et al., 1995), whereas in Ascomycetes the genes are unlinked and even can be located on different chromosomes (for example, Schizosaccharomyces pombe, Wood et al., 2012 (database version 70.2); Saccharomyces cerevisiae, Cherry et al., 2012 (Genome Release R64-1-1)).

Bifactoriality reduces the chance to find a compatible mate and to produce viable zygotes

Because haploids need to differ at both mating-type loci to mate in bifactorial Basidiomycetes, the chance to find a compatible mate is reduced under bifactoriality for a given number of alleles compared with unifactoriality (for evolution of multiallelic mating-type systems see the section 'Evolution of multiallelism in bifactorial systems'). This is also true for the social amoeba Physarum (Moriyama and Kawano,
2010). In contrast, in bifactorial plants and tunicates, bifactoriality increases the chance of mate compatibility, because in those groups compatibility at one locus is enough to ensure successful mating (Barrett and Shore, 2008; Harada et al., 2008; Klaas et al., 2011).

In fungi, if either one of the two loci is biallelic, irrespective of the number of alleles at the other mating type, the proportion of compatible mates in the population at linkage equilibrium cannot exceed 50\% (Stamberg and Koltin, 1973; Kües et al., 2011). Even worse, the probability of finding a compatible mate (for both syngamy and dikaryon viability) is limited by both mating-type loci, so that, for a given number of alleles, bifactoriality decreases the proportion of compatible mates compared with unifactoriality. For example, only a system with at least three alleles at the first and four at the second locus has a proportion of compatible mates in the population that equals the $50 \%$ of the biallelic unifactorial ancestor. Whereas a unifactorial mating type is compatible with $1-p_{i}$ of the population, a bifactorial individual is compatible with only $\left(1-p_{h d}\right)$ $\left(1-p_{p r}\right)$ of the population (with $p_{i}$ describing the frequency of the unifactorial mating type $i$, and $p_{h d}$ and $p_{p r}$ describing the frequencies of the $h d t$ th allele at the $H D$ locus and the prth allele at the $P R$ locus, respectively; Figure 2) (Vuilleumier et al., 2013). This implies that the initial step of bifactorial evolution involved a strong decrease in the proportion of compatible mates. Increased compatibility occurred only after new alleles evolved. The question is therefore why would bifactoriality have evolved?

\section{Bifactoriality can reduce diploid selfing rates}

Bifactoriality reduces the odds of compatibility among the haploid products of a diploid individual and could therefore promote outcrossing (Hsueh et al., 2008) when several gametes from the same and different individuals are physically close. The haploids produced during meiosis in a unifactorial species are of two different mating types and at a 1:1 ratio (Figure 2). A given haploid spore is therefore compatible with $1 / 2$ of the other spores produced by the same diploid individual. A bifactorial individual produces gametes that are compatible on average with only $1 / 4$ of the other gametes from the same individual (that is, two loci, each with two alleles segregating independently). Bifactoriality may therefore reduce selfing at the diploid level (Billiard et al., 2012). 
EVOLUTION OF MULTIALLELISM IN BIFACTORIAL SYSTEMS Bifactoriality facilitates multiallelism

In an outbreeding population, a novel or rare allele has an advantage, as it confers an increased chance to find a compatible mate and should therefore be selected for (Fisher, 1941; May et al., 1999). This is expected to enhance polymorphism at the MAT loci. It is therefore remarkable that, outside of the Basidiomycetes, no fungi are known with multiple alleles at the mating-type locus.

This lack of multiallelism might be caused by constraints on the evolution of new mating-type alleles and/or because other solutions for increased compatibility evolved - such as homothallism for many Ascomycetes. A homothallic fungus produces gametes that are compatible with all other individuals, including its own mitotic descendants, most often by expressing both mating types (Lin and Heitman, 2007) or by producing gametes of either mating type (mating type switching; Haber, 1998). A haploid genotype is then compatible with $100 \%$ of the genotypes in the population; however, this also leads to the possibility of same-clone mating, which does not allow recombination between different genotypes while still incurring the costs of sex. Homothallism thus comes with potential costs (Giraud et al., 2008; Billiard et al., 2011; Billiard et al., 2012).

Billiard et al. (2011) have reviewed the evolutionary forces constraining the number of mating types. They showed that either a control of cytoplasmic inheritance by the mating types, linkage of deleterious mutations to the mating types, or inbreeding can reduce the advantage of novel mating-type alleles, impeding an increase in allele number. Perrin (2012) argued that the proximal functioning of the mating-type system itself might be intrinsically restrictive: the appearance of new alleles that can still make functional heterodimers with extant $H D$ alleles will become increasingly difficult with increasing numbers of mating types.

These arguments hold for both Ascomycetes and Basidiomycetes; however, in the latter group multiallelism did evolve. We argue that bifactoriality might have facilitated the evolution of multiallelism. In Ascomycetes, the pheromone/receptor system is not independent of the allele (idiomorph) at the mating-type locus $(\mathrm{HD}$, alpha-box or
$H M G$ allele), because the latter regulates which pheromone/receptor is expressed (see Figure 4). Changes at either the pheromone/receptor system or the mating-type proteins would thus not increase compatibility because the incompatibility at the other system would remain. In bifactorial fungi, in which the two incompatibility loci act independently and recombine (Fraser et al., 2007), novel mating-type alleles can arise one locus at a time. Similar to the Ascomycete system, in secondary unifactorial Basidiomycete species with linkage between the $P R$ and HD loci, the two systems are coupled and novel alleles will not easily arise. In contrast, in unifactorial systems where the $P R$ locus does not control mating type any more, new alleles can still arise. In other organisms where compatibility is controlled by more than one locus, such as in the Mucoromycotina (HMG and trisporoids pheromones; Idnurm et al., 2008) or green algae (agglutinins and MAT genes; Ferris et al., 2005), similar restrictions may hold as in Ascomycetes.

In mushrooms, a Basidiomycete clade, further genomic changes have evolved favouring polymorphism: mating-type loci are found in two or even three copies in tandem, forming different sub-loci carrying different alleles (Figure 5; Stamberg and Koltin, 1973; Casselton and Kües, 2007; Kües et al., 2011). A limited number of alleles exist at each sub-locus, but, because any sub-locus can allow compatibility, many functional alleles are obtained at the level of the entire locus, increasing the chance to find a compatible mate (Stamberg and Koltin, 1973; May et al., 1999). For instance, nine alleles exist in $S$. commune at each of its two sub-loci of the $P R$ locus, which theoretically yields $9 \times 9=81 P R$ mating-type alleles (Fowler et al., 2004). Recombination between the sub-loci theoretically increases the chance of compatibility among haploids derived from the same diploid parent, hence of inbreeding (in natural isolates compatibility can increase to over 66\%; Stamberg and Koltin, 1973). For the mushroom-forming Basidiomycetes, however, inbreeding is probably not increased, because haploid spores can disperse far from the mushroom before syngamy, favouring panmixis. Even though many basidiospores have local dispersal (for example, Galante et al., 2011; Peay et al., 2012), dispersal seems very efficient (for example, Hallenberg and Kúffer, 2001), as populations show little structure
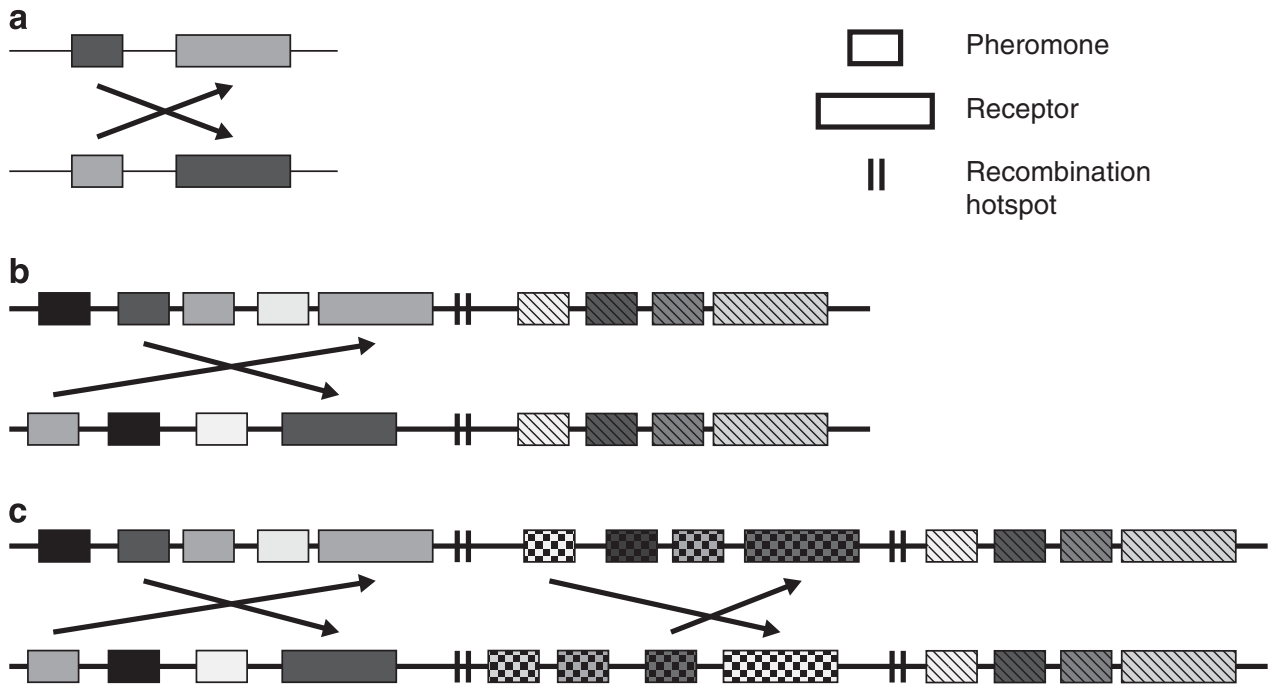

Figure 5 Pheromone/Receptor $(P R)$ mating-type locus in Basidiomycetes. (a) Schematic representation of a system comparable to Ustilago maydis in which each of the two mating-type alleles at the $P R$ locus carries one receptor and one pheromone gene. Each pheromone is compatible with the receptor of the other mating type. (b) System comparable to the Schizophyllum commune PR mating-type locus, which is composed of two sub-loci that each carries one receptor and a variety of pheromone genes. The receptor of each sub-locus is activated by at least one pheromone of any other mating-type allele. Interaction at one sub-locus is sufficient for compatibility. Between the sub-loci a recombination hotspot is located. (c) A system that is composed of three sub-loci comparable to Coprinopsis cinerea. 
(for example, James and Vilgalys, 2001; Kauserud and Schumacher, 2003) and little inbreeding (see Billiard et al., 2012).

\section{Increased probability for viability after syngamy}

In unifactorial species, compatibility at the pheromones/receptor system also indicates compatibility at the $H D$ locus (see Figures $4 \mathrm{a}$ and c), but this is not the case in bifactorial species (Figure $4 \mathrm{~b}$ ). Only after fusion can it be assessed whether the two cells are compatible at the $H D$ locus; any dikaryotic cells carrying the same allele at the $H D$ locus will be inviable. A novel, and therefore rare, $H D$ allele will establish more viable dikaryons and is therefore expected to be selected for. Because a failure to find compatibility at the $H D$ locus leads to inviability of the dikaryon, whereas incompatibility at the $P R$ locus only leads to waiting longer for a compatible partner, selection is expected to be stronger on rare alleles at the HD locus than at the $P R$ locus. Variation at the HD locus is therefore expected to be higher than at the $P R$ locus. In fact, in most Ustilagomycotina and Pucciniomycotina only the $H D$ locus is multiallelic, whereas the $P R$ locus is biallelic ( $U$. maydis (Schirawski et al., 2005), Tremella mesenterica (Wong and Wells, 1985), Sporidiobolus salmonicolor (Coelho et al., 2010)). In Agaricomycotina, there is no clear difference in alleles per mating-type locus. Of the nine species in our data set (see Supplementary Table S1) for which we have estimates for both, four had more alleles at $H D$ than at $P R$, four had more alleles at $P R$ than at $H D$ and one had equal number of alleles, seven, for $H D$ and $P R$.

\section{Reduced inbreeding at the population level}

In addition to increasing the chance of finding a compatible mate under outbreeding, multiple mating-type alleles can allow discrimination based on relatedness within a population. Individuals that have the same mating-type alleles are more likely to be related, and thus multiallelism reduces inbreeding probability. This is especially true in bifactorial species, because relatedness is determined on two independent loci. However, it should be noted that this is a consequence of multiallelism and not of bifactoriality per se. Only when multiple alleles are present, at least at one of the loci, are mating types informative for relatedness. Especially when high numbers of alleles are present, identity at mating-type alleles is a good marker for relatedness. However, it is debatable as to what extent this explanation is plausible in finite and/or structured populations with a low migration rate, as a process should generate linkage disequilibrium with the MAT loci. To test this hypothesis, modelling is required.

\section{REVERSION TO UNIFACTORIAL MATING}

In Basidiomycetes, several reversions from bifactoriality to unifactoriality have been documented (Kües et al., 2011). There are two general ways in which this occurred. The first is when the two loci became linked to each other, as is observed, for example, in the genus Microbotryum (Petit et al., 2012) and in U. hordei (Bakkeren and Kronstad, 1994); the second is by loss of one of the mating-type factors as a genic incompatibility locus, such as happened in, for instance, Coprinellus disseminatus (James et al., 2006). Both types of reversions have occurred multiple times in Basidiomycetes, as seen in molecular analyses of the mating-type genes (Fraser et al., 2007) and in the Basidiomycete phylogeny (Figure 3). In order for unifactoriality to be selected for, the advantages of bifactoriality that we described above (reduced selfing rates and increased compatibility due to multiallelism) should have become less important, or even selected against.

\section{Advantage of increased selfing}

Unifactorial mating types have a higher degree of compatibility for (diploid) selfing, relative to bifactorial mating types, because, in the latter, compatibility is reduced from 50 to $25 \%$. Under certain conditions, selfing might be favoured, which will favour unifactoriality. First, selfing has an automatic 1.5-fold advantage in terms of gene transmission. In hermaphrodites, a gene that ensures selfing will indeed be present in all self-fertilized female gametes, but only in half of the outcrossed offspring can it produce by mating in the male role (Fisher, 1941; Charlesworth, 1980; Aanen and Hoekstra, 2007). This advantage, however, does not apply to isogamous species (Charlesworth, 1980). Second, inbreeding or selfing may be unavoidable under some conditions - for instance, in pathogenic fungi that may often fall as a unique diploid genotype on a given individual host. In such cases, mating among the products of a common meiosis (that is, intra-tetrad mating or automixis) may be the predominant form of selfing (Hood and Antonovics, 2000). Unifactoriality and linkage of the mating-type loci to the centromere will then be selected for, as well as the absence of selection for rare alleles (Hood and Antonovics, 2000; Billiard et al., 2011). Further, selfing might be favoured during colonization of a novel environment, as it avoids breakup of adaptations to the new niche (Giraud et al., 2010). In the plant pathogen $M$. violaceum, for instance, intra-tetrad mating is favoured, which is consistent with the evolution towards unifactoriality (Giraud et al., 2008). Also, bifactorial pathogenic species show that selection for outbreeding is reduced, because there appears to be no strong selection for rare alleles, as often one of the two loci is biallelic (for example, U. maydis; Puhalla, 1970). In fact, most, if not all, secondary unifactorial species with linked mating-type loci are pathogenic, with mating before dispersal, where host-shifts are an important component to speciation, and they present biallelic mating types (Cryptococcus neoformans (Lengeler et al., 2002), Microbotryum violaceum (Hood, 2002), U. hordei (Lee et al., 1999)). No Agaricomycetes have yet been shown to have linkage between the mating-type loci, but the soil-borne plant pathogen Thanatephorus cucumeris (Cantarellales) might harbour this system. This species is biallelic unifactorial ( $\mathrm{Qu}$ et al., 2008), even though in the larger Cantarellales group multiallelic unifactoriality also occurs in mushroom-forming species (for example, Sistotrema coronilla; Whitehouse, 1949). Screens for mating type-associated molecular markers showed that quite a few AFLP loci are associated with each mating-type allele (Julián et al., 1999). This suggests linkage of large genome regions to the mating type, as seen in, for instance, U. hordei and M. violaceum. When selfing is the evolutionary cause for selecting for unifactoriality, one expects this to be due to linkage between the MAT loci rather than due to loss of function of the $P R$ locus in mating-type determinism. Indeed, loss of the $P R$ as a mating-type locus would incur a cost corresponding to dikaryon abortions after syngamy between cells carrying identical alleles at the $H D$ locus. Further, there may be constraints preventing losing the mating function at the $H D$ locus, as it regulates the growth of the dikaryon.

Pseudo-homothallism (or secondary homothallism) is a particular system in which automixis is forced, as two haploid nuclei from one meiotic tetrad are packaged together into one spore. This form of reproduction in Basidiomycetes is so far only known to occur in Agaricomycetes. Almost half of the pseudo-homothallic species in our analysis are unifactorial and the remaining are bifactorial (four and five, respectively; Supplementary Table S1). That unifactoriality in these species might have evolved to assure compatibility during diploid selfing is not supported by the phylogeny. Unifactorial pseudo-homothallics are all positioned in clades with unifactorial 
heterothallic species. Contrary to the above-described intra-tetrad selfers, all studied unifactorial pseudo-homothallic Agaricomycetes remain multiallelic, possibly to increase the chance of compatibility when haploid individuals, which are occasionally produced in pseudo-homothallic species (for example, Raper et al., 1972), meet.

\section{Advantage of increased compatibility in species with few alleles}

Another selective force favouring reversion to unifactoriality could be increasing the chance to find a compatible mate in outcrossing species with few alleles at the mating type loci, due for instance to a bottleneck. Indeed, requiring that two loci carry different alleles is more restrictive than requiring that a single locus carry different alleles (see the section 'Bifactoriality reduces the chance to find a compatible mate and to produce viable zygotes').

In contrast, reduction in the number of incompatibility loci is not beneficial in bifactorial plants and tunicates where compatibility at one locus is enough to ensure successful mating. Some sparse data suggest that unifactorial SI systems in angiosperms might have evolved from multilocus (two or four loci) SI, which seems to be present in basal eudicot and monocot species (reviewed in Yang et al. (2008)), but this remains an open question. To the best of our knowledge, there is no documented case of loss of a functional mating-type locus for social amoeba - the only other group in which compatibility at both loci is necessary for successful mating.

In mushrooms, unifactorial systems have evolved from bifactorial systems multiple times (Figure 3). In at least 16 different families in the Agaricomycetes, both bifactorial and unifactorial species exist and all the unifactorial species studied have multiple alleles at the matingtype locus (except for T. cucumeris, see the section 'Advantage of increased selfing'). In this group of mushroom-forming fungi, due to spore dispersal before mating, outbreeding is much more likely to occur (Giraud et al., 2008). Landing on a compatible mate is of importance for a spore (Wright, 1939; May et al., 1999). A multiallelic unifactorial system is then advantageous relative to a bifactorial system, because the chance of compatibility is greatly increased (Stamberg and Koltin, 1973; Kües et al., 2011).

In the four unifactorial Agaricomycetes in which mating-type loci have been investigated, Coprinellus disseminatus, Pholiota microspora (P. nameko), Phanerochaete chrysosporium and Heterobasidion irregulare (James et al., 2006; Yi et al., 2008; James et al., 2011; Olson et al., 2012), unifactoriality is due to a loss of function in mating-type determinism for the $P R$ locus. These losses are assumed independent events (see Figure 3; James et al., 2011). All four species still carry the genes that are functioning in the pheromone/receptor system, but these are not polymorphic and do not act as a mating-type discriminating locus. The $P R$ system is of importance in pre-mating gamete recognition in the Ascomycetes and in Ustilago, but in mushroom-fungi no extracellular function is known (reviewed in Kothe, 2008; Kües and Navarro-González, 2009). All conspecific mycelia in close contact fuse, and compatibility is assessed after fusion. In such a system, loss of the role of the $P R$ locus in matingtype determinism may be easily achieved. For instance, in $C$. disseminatus, the pheromone receptors appear to be auto-activated (James et al., 2006). However, the $P R$ system in mushrooms is of importance during vegetative growth, during which it probably defines nuclear identity (Debuchy, 1999), and it assures fidelity during vegetative growth by means of growth with clamp connections (Buss, 1987; Erdmann et al., 2012). The nonallelic pheromone/ receptor system is expected to regulate such divisions less well, which might explain the observations that these species often produce fewer or no clamps at all, and hyphae often grow with skewed nucleus ratios
(Hui et al., 1999; Yi et al., 2010). In the unifactorial species $P$. chrysosporium, the HD locus has adopted regulation of some of the functions generally regulated by $P R$ (James et al., 2011).

If the force promoting unifactoriality is for increasing the probability of finding a compatible mate, unifactoriality should evolve by keeping a single locus involved in mating-type determination in combination with multiallelism (see the section 'Bifactoriality facilitatednmultiallelism'). A genotype in which one MAT locus loses its function in mating-type determinism can easily invade a bifactorial population (Vuilleumier et al., 2013). Indeed, unifactoriality due to linkage of the $P R$ and $H D$ loci is usually associated with only two alleles, because a new mating type can only appear by independent mutations both in the $P R$ and $H D$ loci to provide compatibility with extant mating types. The two forces promoting secondary unifactoriality, that is, selfing and increased compatibility, are therefore expected to yield very different systems: either linkage of two biallelic mating-type loci or retention of a single locus for mating-type determinism, with multiple alleles (Figures $2 \mathrm{c}$ and $\mathrm{d}$ ). The maintenance of mating types in such species may be explained by the advantage of preventing same-clone mating (Billiard et al., 2011) but would be at the cost of producing regular abortions of dikaryons, which would allow later re-mating.

\section{Advantage of a rare allele being incidentally associated with a mutation to unifactoriality}

Vuilleumier et al. (2013) analytically investigated the conditions under which a unifactorial mutant - having arisen either by linkage of the mating-type loci or by loss of MAT function of one locus - can invade an outcrossing bifactorial population and induce a transition in the breeding system.

(1) When the unifactorial mutant arises by linkage of the two MAT loci, it has a fitness advantage over the bifactorial mating types because, as recombination is suppressed, it is present in $50 \%$ of the progeny of crosses instead of only in $25 \%$ for mating types having two loci that recombine. Following initial invasion, the unifactorial mutant will also provide advantages to other mating types compatible with itself in the population, as they will also be found in $50 \%$ of the progeny in crosses with the unifactorial mutant, whereas the other mating types will be excluded, reducing the number of mating types in the population. When the linkage captures a rare or novel allele, invasion is even more likely because of frequency-dependent selection for the rare allele. The advantage of the unifactorial system over the bifactorial system, however, decreases with the allelic diversity at each locus (the more polymorphic a bifactorial system is, the higher the chance that it is maintained). Hence, bottlenecks and fragmentation of populations might favour a shift in the breeding strategy from bifactorial to unifactorial, and secondary unifactorial species would bear few MAT alleles. However, situations of two mutations (novel MAT allele and linkage of the two MAT loci) may be infrequent. Furthermore, the assumption of outcrossing may not be generally applicable; we have discussed above that unifactoriality may have advantages under selfing. In fact, as discussed in Vuilleumier et al. (2013), most bifactorial species with two linked mating types are pathogenic (M. violaceum, Cryptococcus, U. hordei, (Bakkeren and Kronstad, 1994; Fraser et al., 2007; Petit et al., 2012)), and therefore likely encountering mate limitation on a given host individual and thus likely undergoing diploid selfing.

(2) When the bifactorial mutant arose by loss of function of one locus in mating-type determinism, its invasion is likely under a broad range of conditions, because compatibility is increased when a single locus controls incompatibility. Under this scenario, transition is easily 
achieved and is associated with a drastic reduction in the number of mating types (all mating-type alleles associated with the MAT locus that has lost its mating-type function are excluded). This corresponds to the scenario discussed in the section 'Advantage of increased compatibility in species with few alleles' (see also Figure 6). Under this scenario, the allelic diversity at the remaining MAT locus determines the number of mating types that can remain high, as observed, for example, in C. disseminatus (James et al., 2006).

\section{INTERMEDIATE SYSTEMS}

An intermediate system between uni- and bifactoriality was recently described by Coelho et al. (2010). Some species from the Sporidiobolales (Microbotryomycetes) have two alleles at the $P R$ locus, and each allele is linked to multiple but specific alleles at the $H D$ locus. Recombination is possible between the $P R$ and $H D$ loci but appears extremely rare. This strongly reminds of the $U$. maydis system with a biallelic $P R$ locus and multiple $H D$ alleles, but with part of the $H D$ alleles fully associated with one $P R$ allele and the others only with the other $P R$ allele. This system is most likely derived from a bifactorial system, although it cannot be ruled out that this system is intermediate between primary unifactorial and bifactorial as suggested by Coelho et al. (2010). Linkage has two consequences: (1) it increases compatibility under outcrossing, because compatibility at the $P R$ locus tends to lead to compatibility at the $H D$ locus, and (2) it increases the possibility for selfing from 25 to $50 \%$.

It is unclear why the HD mating type should remain multiallelic in such a system. If the $P R$ locus is completely linked to the $H D$ one, the advantage of new alleles as described in the section 'Bifactoriality facilitates multiallelism' does not hold. One expects that some $H D$ alleles will be lost by drift to the eventual retention of two forms.

\section{TESTING HYPOTHESES}

\section{Mating system versus breeding system}

One way of testing the hypotheses above is by investigating the mating systems (selfing versus outcrossing) of species with various breeding systems (uni- versus bifactorial). Outcrossing, as assessed with molecular markers in natural populations, should be associated with bifactoriality and multiallelism, whereas selfing species should be unifactorial with only two alleles (Figure 6). This seems to be the case so far (see phylogeny Figure 3 and Supplementary Table S1), but still too few fungal species have been investigated for their mating systems in nature (Billiard et al., 2012). Clades especially, in which both breeding systems are present, as is expected, for instance, in Cantarellales (see the section 'Advantage of increase selfing'), are good candidates for testing this association.

\section{Proximal mechanisms}

Another way of testing the hypothesis that the breeding system depends on the mating system is by investigating the proximal mechanisms of unifactoriality in several groups of Basidiomycetes, that is, in mushrooms and in more basal groups. One expects linkage of two loci to be associated with diploid selfing, and loss of function of one locus to be associated with outcrossing, as assessed in natural populations with molecular markers (Figure 6).

\section{Study convergent evolution of bifactoriality}

A study of the Ascomycete species Diaporthe perniciosa showed that progeny from one mating could be assigned to four compatibility groups, as is expected under bifactoriality (Cayley, 1931; Debuchy et al., 2010). Investigating this species might yield interesting insights in a group so distantly related to Basidiomycetes. It can help elucidate whether bifactoriality evolved after the separation between the Ascomycota and the Basidiomycota. If bifactoriality evolved separately in these species, as is expected from the phylogeny, it would provide an extra independent system in which the benefits of multiple loci for mate incompatibility can be studied.

\section{The bi- and multiallelic genus Tilletia}

The unifactorial genus Tilletia is another example of an interesting system for exploring the above-mentioned aspects of fungal mating. It includes both biallelic (for example, T. laevis and T. tritici) and multiallelic species (for example, T. indica; Garrett and Bowden, 2002; Carris et al., 2006), thus offering the possibility of testing the proposed associations of multiallelism and biallelism with secondary

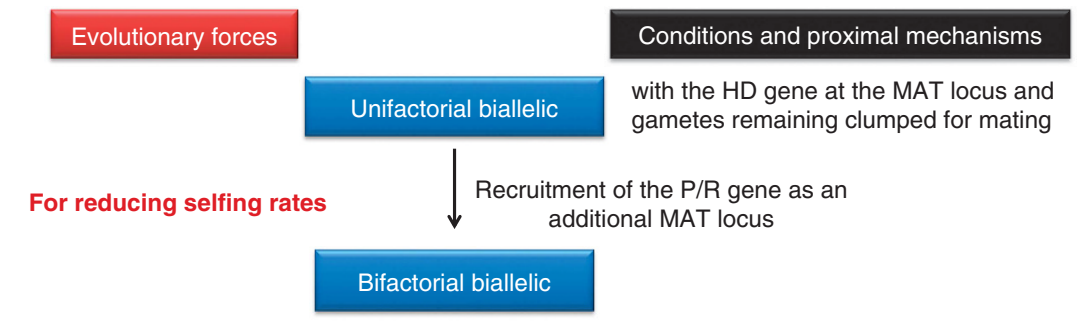

For increasing the probability to fall on a compatible mate

Dispersing gametes

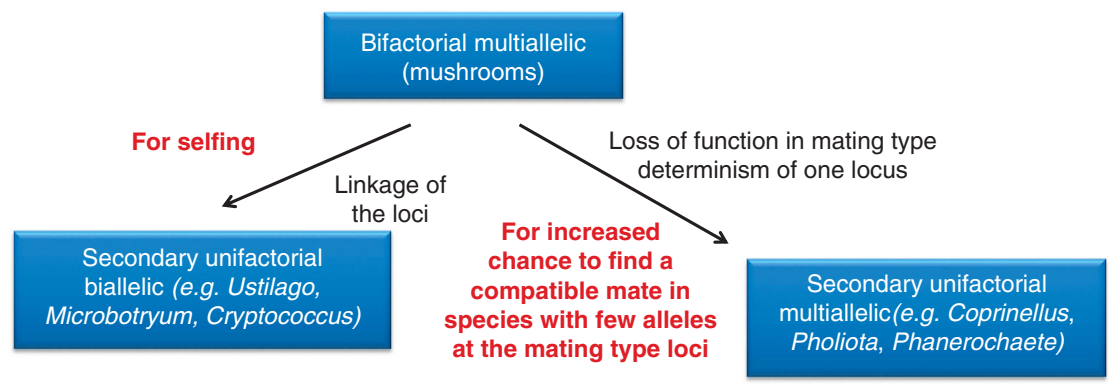

Figure 6 Evolutionary and proximal forces acting on the evolution of uni- versus bifactoriality. See text for more details. 
unifactoriality due to loss of function or linkage of the mating types, respectively. First of all, it is important to identify the ancestral state of this system-for instance, using trans-specific polymorphism, which makes it possible to date the origin of the alleles (Devier et al., 2009). Was it multiallelic for both, for one, or for neither of the mating-type loci? This could indicate whether mating types have recently arisen or if several mating types existed for several speciation events.

As explained in the section 'Bifactoriality facilitates multiallelism', the potential for multiallelism is constrained by, among others, the proximal mechanisms of unifactoriality. To our knowledge, it is unknown whether unifactoriality in Tilletia species evolved due to linkage or due to loss of a role for one of the loci in mating-type determinism. If the two mating-type loci became linked, this would be the first example of a multiallelic system with linked mating-type loci. For $T$. indica, with four mating-type alleles, compatibility between all four types implies that four different alleles must exist at each of the $H D$ and $P R$ loci. Assuming that the appearance of new alleles is difficult after linkage (see section 'Genomic changes'), the presence of multiple mating-type alleles implies multiple independent linkage events between pre-existing alleles.

On the other hand, if only one of the MAT loci remains in control of mating-type determinism, these will be the first species described with a biallelic system in which one MAT locus loses its function in mate recognition. It would then be interesting to investigate why some of the species reverted from an assumed multiallelic ancestral state to a biallelic system, whereas the others did not. The number of mating types in T. indica is only four, which is low compared with the number of mating types in other multiallelic unifactorial species. This might be due to an advantage of local mating and inbreeding as described in section 'Advantage of increased selfing', although loci might have been lost during transition as well. Loss of functionality of the $P R$ locus in a biallelic population is not expected, as without premating recognition many of the formed zygotes will be infertile (see the section 'Advantage of a rare allele being incidentally associated with a mutation to unifactoriality').

\section{CONCLUSIONS}

Breeding systems in fungi show variation in both the number of loci controlling compatibility (one or two) and in the number of alleles that are located at each locus. The bifactorial, two-loci system appears to have evolved only once in fungi and has reverted multiple times towards a unifactorial system. Two different forms of secondary unifactoriality evolved, in which either the two mating-type loci became physically linked or one of the two loci lost its function. We argue that each of these two types evolved under different environmental selection pressures: loss of function for increased outbreeding potential versus linkage for increased selfing (Figure 6).

Increasing knowledge on breeding systems in various groups of fungi through whole-genome sequencing efforts, as well as intensive species screenings, makes it possible to investigate the different hypotheses we outline in this paper. Multiallelic unifactoriality is predicted to be associated with a loss-of-function origin in which outbreeding is optimized. Linkage is associated with a strong reduction in the number of alleles owing to the restrictions on generating new alleles and the benefits of selfing, which does not require high numbers of alleles. Population genetic studies are critically needed to assess whether selfing or outbreeding most often occur in nature and in association with various genetic modes of inheriting mating compatibility factors.

\section{DATA ARCHIVING}

There were no data to deposit.

\section{CONFLICT OF INTEREST}

The authors declare no conflict of interest.

\section{ACKNOWLEDGEMENTS}

We thank Spencer Barrett, Duur Aanen and Manuela Lopez-Villavicencio for useful discussions. We also thank two anonymous referees for comments on an earlier version of this manuscript. TG acknowledges grant FungiSex ANR-09-0064-01, MEH the grant NSF-DEB 0747222, SV the SNSF grant \#PZ00P3_139421/1, SB acknowledges post-doctoral grants from the CNRS and BN grants from NWO-ALW and the Carl Tryggers Stiftelse. We apologize to all those colleagues whose work we may have failed to cite in this article.

Aanen DK, Hoekstra RF (2007). Why sex is good: on fungi and beyond. In: Heitman J, Kronstad JW, Taylor JW, Casselton LA (eds) Sex in Fungi: molecular determination and evolutionary implications. ASM Press: Washington DC, USA, pp 527-534.

Bakkeren G, Kronstad JW (1994). Linkage of mating-type loci distinguishes bipolar from tetrapolar mating in basidiomycetous smut fungi. Proc Natl Acad Sci USA 91 7085-7089.

Barrett SCH (2010). Understanding plant reproductive diversity. Phil Trans $R$ Soc B 365 99-109.

Barrett SCH, Shore JS (2008). New insights on heterostyly: comparative biology, ecology and genetics. In: Franklin-Tong V (ed) Self-incompatibility in flowering plants. SpringerVerlag: Berlin, Germany, pp 3-32.

Begerow D, Stoll M, Bauer R (2006). A phylogenetic hypothesis of Ustilaginomycotina based on multiple gene analyses and morphological data. Mycologia 98: 906-916.

Billiard S, López-Villavicencio M, Devier B, Hood ME, Fairhead C, Giraud T (2011). Having sex, yes, but with whom? Inferences from fungi on the evolution of anisogamy and mating types. Biol Rev 86: 421-442.

Billiard S, López-Villavicencio M, Hood ME, Giraud T (2012). Why sex, outcrossing and mating types? Unsolved questionsin fungi and beyond. J Evol Biol 25: 1020-1038.

Bölker M, Urban M, Kahmann R (1992). The a mating type locus of U. maydis specifies cell signaling components. Cell 68: 441-450.

Boutin T, Le Rouzic A, Capy P (2012). How does selfing affect the dynamics of selfish transposable elements? Mobile DNA 3: 5.

Busch JW (2011). Demography, pollination, and Baker's law. Evolution 65: 1511-1513. Buss LW (1987). The evolution of individuality. Princeton University Press: Princeton, USA Carris LM, Castlebury LA, Goates BJ (2006). Nonsystemic bunt fungi-Tilletia indica and T. horrida: a review of history, systematics, and biology. Annu Rev Phytopathol 44: 113-133.

Casselton LA, Kües U (2007). The origin of multiple mating types in model mushrooms Coprinopsis cinerea and Schizophyllum commune. In: Heitman J, Kronstad JW, Taylor JW, Casselton LA (eds) Sex in Fungi: Molecular determination and evolutionary implications. ASM Press: Washington D.C., pp 283-300.

Cayley DM (1931). The inheritance of the capacity for showing mutual aversion between mono-spore mycelia of Diaporthe perniciosa (Marchal). J Genet 24: 1-63.

Charlesworth B (1980). The cost of sex in relation to mating system. J Theor Biol 84 655-671.

Charlesworth D, Charlesworth B (1995). Quantitative genetics in plants: The effect of the breeding system on genetic variability. Evolution 49: 911-920.

Cherry JM, Hong EL, Amundsen C, Balakrishnan R, Binkley G, Chan ET et al. (2012) Saccharomyces Genome Database: the genomics resource of budding yeast. Nucleic Acids Res 40: D700-D705.

Cisar CR, TeBeest DO (1999). Mating system of the filamentous ascomycete, Glomerella cingulata. Curr Genet 35: 127-133.

Coelho MA, Sampaio JP, Gonçalves P (2010). A deviation from the bipolar-tetrapolar mating paradigm in an early diverged basidiomycete. PLoS Genet 6: e1001052.

Coppin E, Debuchy R, Arnaise S, Picard M (1997). Mating-types and sexual development in filamentous ascomycetes. Microbiol Mol Biol Rev 61: 411-428.

Czárán TL, Hoekstra RF (2004). Evolution of sexual asymmetry. BMC Evol Biol 4: 34-34.

Debuchy R (1999). Internuclear Recognition: A Possible Connection between Euascomycetes and Homobasidiomycetes. Fungal Genet Biol 27: 218-223.

Debuchy R, Berteaux-Lecellier V, Silar P (2010). Mating systems and sexual morphogenesis in ascomycetes. In: Borkovich KA, Ebbole DJ, Momany M (eds) Cellula and molecular biology of filamentous fungi. ASM Press: Washington DC, USA, pp 501-535.

Devier B, Aguileta G, Hood ME, Giraud T (2009). Ancient trans-specific polymorphism at pheromone receptor genes in Basidiomycetes. Genetics 181: 209-223.

Dyer PS (2008). Evolutionary biology: Genomic clues to original sex in fungi. Curr Biol 18 R207-R209.

Erdmann S, Freihorst D, Raudaskoski M, Schmidt-Heck W, Jung E-M, Senftleben D et al. (2012). Transcriptome and functional analysis: Mating in the basidiomycete Schizophyllum commune. Eukaryot Cell 11: 571-589.

Feldbrügge M, Kämper J, Steinberg G, Kahmann R (2004). Regulation of mating and pathogenic development in Ustilago maydis. Curr Opin Microbiol 7: 666-672.

Ferris PJ, Waffenschmidt S, Umen JG, Lin H, Lee J-H, Ishida K et al. (2005). Plus and minus sexual agglutinins from Chlamydomonas reinhardtii. The Plant Cell Online 17: $597-615$ 
Fisher RA (1941). Average excess and average effect of a gene substitution. Annals of Eugenics 11: 53-63.

Fowler TJ, DeSimone SM, Mitton MF, Kurjan J, Raper CA (1999). Multiple sex pheromones and receptors of a mushroom-producing fungus elicit mating in yeast. Mol Biol Cell 10: 2559-2572.

Fowler TJ, Mitton MF, Rees El, Raper CA (2004). Crossing the boundary between the B alpha and B beta mating-type loci in Schizophyllum commune. Fungal Genet Biol 41: 89-101.

Fraser JA, Hsueh Y-P, Findley KM, Heitman J (2007). Evolution of mating-type locus: the basidiomycetes. In: Heitman J, Kronstad JW, Taylor JW, Casselton LA (eds) Sex in Fungi: Molecular determination and evolutionary implications. ASM Press: Washington DC, USA, pp 19-34.

Galante TE, Horton TR, Swaney DP (2011). 95\% of basidiospores fall within $1 \mathrm{~m}$ of the cap: a field-and modeling-based study. Mycologia 103: 1175-1183.

Garrett KA, Bowden RL (2002). An Allee effect reduces the invasive potential of Tilletia indica. Phytopathology 92: 1152-1159.

Gibson MR, Richardson DM, Pauw A (2012). Can floral traits predict an invasive plant's impact on native plant-pollinator communities? J Ecol 100: 1216-1223.

Gioti A, Mushegian AA, Strandberg R, Stajich JE, Johannesson H (2012). Unidirectional evolutionary transitions in fungal mating systems and the role of transposable elements. Mol Biol Evol 29: 3215-3226.

Giraud T, Gladieux P, Gavrilets S (2010). Linking the emergence of fungal plant diseases with ecological speciation. Trends Ecol Evol 25: 387-395.

Giraud T, Yockteng R, Lopez-Villavicencio M, Refregier G, Hood ME (2008). Mating system of the anther smut fungus Microbotryum violaceum: selfing under heterothallism. Eukaryot Cell 7: 765-775.

Gonçalves-Sá J, Murray A (2011). Asymmetry in sexual pheromones is not required for ascomycete mating. Curr Biol 21: 1337-1346.

Haber JE (1998). Mating-type gene switching in Saccharomyces cerevisiae. Annu Rev Genet 32: 561-599.

Hallenberg N, Kúffer N (2001). Long-distance spore dispersal in wood-inhabiting Basidiomycetes. Nord J Bot 21: 431-436.

Harada Y, Takagaki Y, Sunagawa M, Saito T, Yamada L, Taniguchi H et al. (2008). Mechanism of self-sterility in a hermaphroditic chordate. Science 320: 548-550.

Heitman J, Kronstad JW, Taylor JW, Casselton LA (eds) (2007). Sex in fungi: molecular determination and evolutionary implicationsASM Press: Washington D.C., USA.

Heitman J, Sun S, James TY (2013). Evolution of fungal sexual reproduction. Mycologia 105: $1-27$

Hibbett DS, Binder M, Bischoff JF, Blackwell M, Cannon PF, Eriksson OE et al. (2007). A higher-level phylogenetic classification of the Fungi. Mycol Res 111: 509-547.

Hibbett DS, Donoghue MJ (2001). Analysis of character correlations among wood decay mechanisms, mating systems, and substrate ranges in homobasidiomycetes. Syst Biol 50: $215-242$.

Hood ME (2002). Dimorphic mating-type chromosomes in the fungus Microbotryum violaceum. Genetics 160: 457-461.

Hood ME, Antonovics J (2000). Intratetrad mating, heterozygosity, and the maintenance of deleterious alleles in Microbotryum violaceum ( = Ustilago violacea). Heredity $\mathbf{8 5}$ 231-241.

Hsueh Y-P, Fraser JA, Heitman J (2008). Transitions in sexuality: recapitulation of an ancestral tri- and tetrapolar mating system in Cryptococcus neoformans. Eukaryot Cell 7: $1847-1855$.

Hui C, Yamamoto H, Ohta T, Takeo K, Kitamoto Y (1999). Nuclear selection in monokaryotic oidium formation from dikaryotic mycelia in a basidiomycete, Pholiota nameko. Mycoscience 40: 199-203.

Idnurm A, Walton FJ, Floyd A, Heitman J (2008). Identification of the sex genes in an early diverged fungus. Nature 451: 193-196.

James TY, Lee M, van Diepen LTA (2011). A single mating-type locus composed of homeodomain genes promotes nuclear migration and heterokaryosis in the white-rot fungus Phanerochaete chrysosporium. Eukaryot Cell 10: 249-261.

James TY, Srivilai P, Kües U, Vilgalys R (2006). Evolution of the bipolar mating system of the mushroom Coprinellus disseminatus from its tetrapolar ancestors involves loss of mating-type-specific pheromone receptor function. Genetics 172: 1877-1891.

James TY, Vilgalys R (2001). Abundance and diversity of Schizophyllum commune spore clouds in the Caribbean detected by selective sampling. Mol Ecol 10: 471-479.

Julián MC, Acero J, Salazar O, Keijer J, Rubio V (1999). Mating type-correlated molecular markers and demonstration of heterokaryosis in the phytopathogenic fungus Thanatephorus cucumeris (Rhizoctonia solani) AG 1-IC by AFLP DNA fingerprinting analysis. J Biotechnol 67: 49-56

Kauserud H, Schumacher T (2003). Genetic structure of Fennoscandian populations of the threatened wood-decay fungus Fomitopsis rosea (Basidiomycota). Mycol Res 107 155-163.

Klaas M, Yang B, Bosch M, Thorogood D, Manzanares C, Armstead IP et al. (2011). Progress towards elucidating the mechanisms of self-incompatibility in the grasses: further insights from studies in Lolium. Ann Bot 108: 677-685.

Kothe $E$ (2008). Sexual attraction: On the role of fungal pheromone/receptor systems ( $A$ review). Acta microbiologica et immunologica Hungarica 55: 125-143.

Kües U, James TY, Heitman J (2011). Mating type in basidiomycetes: Unipolar, bipolar, and tetrapolar paterns of sexuality. In: Pöggeler S, Wöstemeyer J (eds) Evolution of fungi and fungal-like organisms, the mycota XIV. Springer-Verlag: Berlin, Heidelberg Germany.
Kües U, Navarro-González M (2009). Communication of fungi on individual, species, kingdom, and above kingdom level. In: Anke T, Weber D (eds) Physiology and Genetics. Springer-Verlag: Berlin Heidelberg, Germany. Vol. 15, pp 79-106.

Lee N, Bakkeren G, Wong K, Sherwood JE, Kronstad JW (1999). The mating-type and pathogenicity locus of the fungus Ustilago hordei spans a 500-kb region. Proc Natl Acad Sci USA 96: 15026.

Lengeler K, Fox D, Fraser J, Allen A, Forrester K, Dietrich F et al. (2002). Mating-type locus of Cryptococcus neoformans: a step in the evolution of sex chromosomes. Eukaryot Cell 1: 704

Lin X, Heitman J (2007). Mechanisms of homothallism in fungi and transitions between heterothallism and homothallism. In: Heitman J, Kronstad JW, Taylor JW, Casselton LA (eds) Sex in Fungi: Molecular determination and evolutionary implications. ASM Press: Washington DC, pp 35-57.

Matheny PB, Curtis JM, Hofstetter V, Aime MC, Moncalvo JM, Ge ZW et al. (2006). Major clades of Agaricales: a multilocus phylogenetic overview. Mycologia 98: 982-995.

Matheny PB, Wang Z, Binder M, Curtis JM, Lim YW, Henrik Nilsson R et al. (2007). Contributions of rpb2 and tef 1 to the phylogeny of mushrooms and allies (Basidiomycota, Fungi). Mol Phylogen Evol 43: 430-451.

May G, Shaw F, Badrane H, Vekemans X (1999). The signature of balancing selection: Fungal mating compatibility gene evolution. Proc Natl Acad Sci USA 96: 9172-9177.

Metzenberg R, Glass N (1990). Mating type and mating strategies in Neurospora. Bioessays 12: 53-59.

Moriyama Y, Kawano S (2010). Maternal inheritance of mitochondria: multipolarity, multiallelism and hierarchical transmission of mitochondrial DNA in the true slime mold Physarum polycephalum. J Plant Res 123: 139-148.

Nygren K, Strandberg R, Wallberg A, Nabholz B, Gustafsson T, García D et al. (2011). A comprehensive phylogeny of Neurospora reveals a link between reproductive mode and molecular evolution in fungi. Mol Phylogen Evol 59: 649-663.

Olson A., Aerts A, Asiegbu F, Belbahri L, Bouzid O, Broberg A et al. (2012). Insight into trade-off between wood decay and parasitism from the genome of a fungal forest pathogen. New Phytol 194: 1001-1013.

Otto SP (2009). The evolutionary enigma of sex. Am Nat 174: S1-S14.

Peay KG, Schubert MG, Nguyen NH, Bruns TD (2012). Measuring ectomycorrhizal fungal dispersal: macroecological patterns driven by microscopic propagules. $\mathrm{Mol} E \mathrm{Eol} 21$ : $4122-4136$.

Perrin N (2012). What uses are mating types? The "developmental switch" model. Evolution 66: 947-956.

Petit E, Giraud T, de Vienne DM, Coelho MA, Aguileta G, Amselem J et al. (2012). Linkage to the mating-type locus across the genus Microbotryum: Insights into non-recombining chromosomes. Genetics 66: 3519-3533.

Puhalla JE (1970). Genetic studies of the b incompatability locus of Ustilago maydis. Genet Res 16: 229-232.

Qu P, Yamashita K, Toda T, Priyatmojo A, Kubota M, Hyakumachi M (2008). Heterokaryon formation in Thanatephorus cucumeris (Rhizoctonia solani) AG-1 IC. Mycol Res 112: 1088-1100.

Raper CA, Raper JR, Miller RE (1972). Genetic analysis of the life cycle of Agaricus bisporus. Mycologia 64: 1088-1117.

Raper JR (1966). Genetics of sexuality in higher fungi. Ronald Press: New York.

Richards AJ (2003). Apomixis in flowering plants: an overview. Phil Trans $R$ Soc $B$ 358: 1085-1093.

Schirawski J, Heinze B, Wagenknecht M, Kahmann R (2005). Mating type loci of Sporisorium reilianum: novel pattern with three a and multiple b specificities. Eukaryot Cell 4: 1317-1327.

Stamberg J, Koltin Y (1973). The organisation of the incompatibility factors in higher fungi: the effect of structure and symmetry on breeding. Heredity 30: 15-26.

Tsong AE, Miller MG, Raisner RM, Johnson AD (2003). Evolution of a combinatorial transcriptional circuit: a case study in yeasts. Cel/ 115: 389-399.

Vuilleumier S, Alcala N, Niculita-Hirtzel H (2013). Transitions from reproductive systems governed by two self-incompatible loci to one in fungi. Evolution 67: 501-516.

Wendland J, Vaillancourt L, Hegner J, Lengeler K, Laddison K, Specht C et al. (1995). The mating-type locus $B \alpha 1$ of Schizophyllum commune contains a pheromone receptor gene and putative pheromone genes. EMBO J 14: 5271.

Whitehouse HLK (1949). Multiple-allelomorph heterothallism in the fungi. New Phytol 48 : 212-244.

Wood V, Harris MA, McDowall MD, Rutherford K, Vaughan BW, Staines DM et al. (2012). PomBase: a comprehensive online resource for fission yeast. Nucleic Acids Res 40: D695-D699.

Wong GJ, Wells K (1985). Modified bifactorial incompatibility in Tremella mesenterica. Transactions of the British Mycological Society 84: 95-109.

Wright S (1939). The distribution of self-sterility alleles in populations. Genetics 24 538-552.

Yang B, Thorogood D, Armstead I, Barth S (2008). How far are we from unravelling selfincompatibility in grasses? New Phytol 178: 740-753.

Yi R, Mukaiyama H, Tachikawa T, Shimomura N, Aimi T (2010). A-Mating-type gene expression can drive clamp formation in the bipolar mushroom Pholiota microspora (Pholiota nameko). Eukaryot Cell 9: 1109-1119.

Yi R, Tachikawa T, Ishikawa M, Mukaiyama H, Bao D, Aimi T (2008). Genomic structure of the A mating-type locus in a bipolar basidiomycete, Pholiota nameko. Mycol Res 113: 240-248. 